\title{
Building a culture of innovation in learning and teaching technologies through an innovators group
}

\author{
Birgit Loch, Belinda Thompson, Christopher Bridge, Dell Horey, Brianna \\ Julien, Julia Agolli
}

La Trobe University

\begin{abstract}
Innovation was seen as crucial for universities even before the COVID-19 global pandemic, to widen participation within massification strategies, to deliver graduates that meet the needs of economies and to justify increased fees in response to reduced government funding. Innovation will become increasingly important as universities contribute to the post-pandemic recovery of their communities and nations and need to find new avenues for research funding with less reliance on governments. In this paper, we describe our first steps towards developing a culture of innovation in learning and teaching across science, health, and engineering disciplines by bringing together and empowering a group of mostly junior academics. We describe achievements of this group, indicate key success factors, and discuss next steps.
\end{abstract}

Keywords: Culture of innovation, innovators group, culture development, dissemination.

\section{Culture and Building a Culture of Innovation}

An innovation strategy is unlikely to succeed if the underlying organisational culture is risk averse; the famous quote "culture eats strategy for breakfast" credited by some to Peter Drucker, reflects this and is relevant to higher education contexts that are traditionally risk averse for several reasons. These include: regulatory and policy obligations; historical adverse experiences with risk; reputational and financial implications if students are negatively affected; fears of loss of control when change momentum begins; and the risk of failure that innovation introduces.

Organisational culture can be described as the way things are done in a workplace and results from shared learning experiences over time. Organisational culture has been defined by Schein (1988) as a pattern of basic assumptions that has developed over time when processes and priorities are adopted by assumption. Christensen (2006) said that organisational culture "affects and regulates the way members of the organisation think, feel and act within the framework of that organisation" (p. 1), adding that such culture is dynamic in the sense that it can "evolve with new experiences" (p. 2), as "the culture is an organisation's response to the problems it has confronted" (p. 4). So how can cultural change in an organisation be initiated and influenced? The business literature suggests that attempts to change culture are unlikely to succeed if a culture is directly attacked, rather a more strategic approach is needed. Schaffer strongly argues against transforming a whole culture and instead suggests starting with a few smaller successes from which to base and expand cultural change (Shaffer, 2012). The creation of a team of people given a new task to represent the type of problems the organisation will face in the future has been shown to be successful (Christensen, 2006). If such a team succeeds in developing an effective process for addressing a new problem, rather than being dispersed the team should address the same task again and again to develop even greater effectiveness. The more this is repeated, the more likely the group will create a stronger new culture (Christensen, 2006).

Innovation was seen as crucial for universities before the COVID-19 global pandemic, to widen participation within massification strategies, to deliver graduates that meet the needs of economies and to justify increased fees in response to reduced government funding (Tierney \& Lanford, 2016; Winks, Green \& Dyer, 2020). In the context of innovation in higher education, Setser and Morris (2015) discuss the need to shift from improvement to innovation and stress the importance of leadership at all levels. To catalyse, enable and sustain an effective culture of innovation over time, several factors are identified that work together to promote or constrain the desired culture. In the context of private higher education in Jordan, Elrehail et al. (2017) found that while aspects of transformational leadership (inspirational motivation, idealised influence, intellectual stimulation and personal attention) and knowledge sharing (giving and donating knowledge) increase levels of innovation in isolation, when these are used in combination the cultural change is even more effective. 
The process of innovation should be intentional and begin with the outcome in mind according to Aldridge (2018), who also encourages processes that are inclusive, and engage everyone with an investment in the outcome, and continuous, rather than discrete actions ending upon execution. Winks et al. (2020) discuss the role of formal and informal spaces to foster interdisciplinary innovation and creativity in educational practice and conclude that faculty and institutions need to collaborate to reimagine spaces for faculty peer learning. Pataraia et al. (2015) find that personal networks are dynamic communities important for academics' learning and influence application of new teaching technologies and teaching and assessment strategies.

We use Lewitt et al.'s (2014, p. 4) definition of innovation in higher education learning and teaching: innovation is "a new, sustainable approach that has led to an overall improvement in the student experience, and which is supported by evidence" to describe our approach to a strategy of cultural change. This is a retrospective view. We do not yet know if this approach is sustainable or will lead to an overall improvement, but this is a challenge for all strategies that are still under trial and is one of the major difficulties for new approaches where evidence of effectiveness is yet to be established. Innovation often means leaving our comfort zones.

\section{The Innovators Group}

La Trobe University has four cultural qualities, one of which is Innovation. However, like many institutions, innovation has been the one most difficult to address since it means taking risks and creating safe spaces for failure in a risk-averse environment. Back in 2018, there were no mechanisms in place to foster innovation in learning and teaching. Most effort had focused on improvement of research rankings, which was to the detriment of teaching and the student experience. Little discussion about learning and teaching occurred across disciplines and practice sharing was limited - in fact, Schools and Departments within the College of Science, Health and Engineering (SHE), one of two Colleges, operated largely as silos. It was in this environment that several initiatives were commenced to build an organisational culture that values learning and teaching, including building a deliberate culture of innovation in learning and teaching technologies across the multidisciplinary College described in this paper.

The idea of bringing lecturers known for their innovative ideas and practice together was inspired by experiences shared at the 2017 Australian Council of Deans of Science Learning and Teaching Leaders Conference by Teri Balser, then Dean of Learning and Teaching at Curtin University. In need of ideas to make savings for the faculty, Teri had formed two staff groups: the Horizon Innovation Team (HIT) and the Rapid Action Team (RAT). RAT sought short- and medium-term suggestions for budget efficiencies while HIT focused on big, blue-sky ideas to inform long-term initiatives for efficiencies. Both groups operated in a threemonth window and produced a final implementation report for approval by the senior executive.

In the SHE College, a call to the School Directors of Learning and Teaching to nominate one or two most innovative lecturers in the use of technologies for learning and teaching resulted in an initial membership of 17 academics from across the seven Schools. Almost all were junior academics at levels A or B. When the group formed in early 2018, it was initially called the "technology in teaching innovators group".

From the outset the direction of the group was open - just the formation of such a group was itself innovative. To create a sense of ownership among the group, at the first meeting in April 2018, members were asked to share the innovative ways they were using technologies in their teaching. The level of experience varied significantly; some had been trialing several technologies in different ways while others were more hesitant. Discussion continued about technologies members would like to use in their teaching, and what should be the focus of the group. When asked what they would like to see the group achieve several members said that they wanted to challenge the status quo and have impact beyond their own teaching. This was an early indication that this group could be important in keeping the College at the cutting edge in tertiary education methods.

Following that first meeting, a six-weekly meeting cycle was established. There was always an agenda with actions captured and follow-up reported. Meetings were chaired initially by the College Deputy Provost Learning and Teaching and later by the Senior Advisor Learning and Teaching. The group was designed to follow a community of practice approach (Wenger, 1998; Wenger et al., 2002) where sharing practice was a key feature as reciprocity encourages interaction (Pataraia et al., 2015). The regular meetings include at least one presentation from a member or invited guest to foster ideas and discussion, and a "hot topics" session, to raise any issues with a technology and if necessary, follow up. While the agenda is organised by technologies, pedagogical considerations, i.e., how to improve the student experience and how the technology could be used to achieve better student engagement and outcomes are at the forefront of discussions. Presentations regularly 
include evaluation of the student experience of a given innovation. Membership of the group expanded three months after the initial meeting to include self- and other nominations. Over the last three years the group has undergone several changes, reflecting the transient nature of many academic communities. There are now 50 formal members with 11 of the original 17 members remaining, five in that group have left the university.

\section{Impact of the Group}

There are some early measures of the impact of the group so far: the range of technologies adopted; members' contributions to the shift to online teaching; and the achievements of individual members. The impact of reciprocity is evident in Figure 1 which represents each academic who commenced using a technology that has found subsequent adoption across the College, as a result of it being championed by a member(s) of the innovators group. Each circle represents a teaching academic; colour represents proximity to the innovators group where the initiators and most active innovators are marked in orange, the remaining initial innovators in green, and early adopters in yellow. Grey marks a second wave of adoption: academics who started to use the technology because an innovator or early adopter encouraged them to do so. Letters represent some of the technologies explored, including T - Tablet; S - SRES (Student Relationship Engagement System); P - Polling; M - MS Teams; L - Lightboard; H - H5P; C - Camtasia; 360 - 360 camera. Multiple letters indicate the academic is using more than one technology. While this picture is incomplete it shows how the Innovators Group has been able to cross the previous School silos and extend beyond group members with the use of different teaching technologies.

Figure 1. Individual staff members engaged with technologies who were first explored by the innovators are represented by a circle. Letters represent technologies, colours proximity to the Innovators Group.

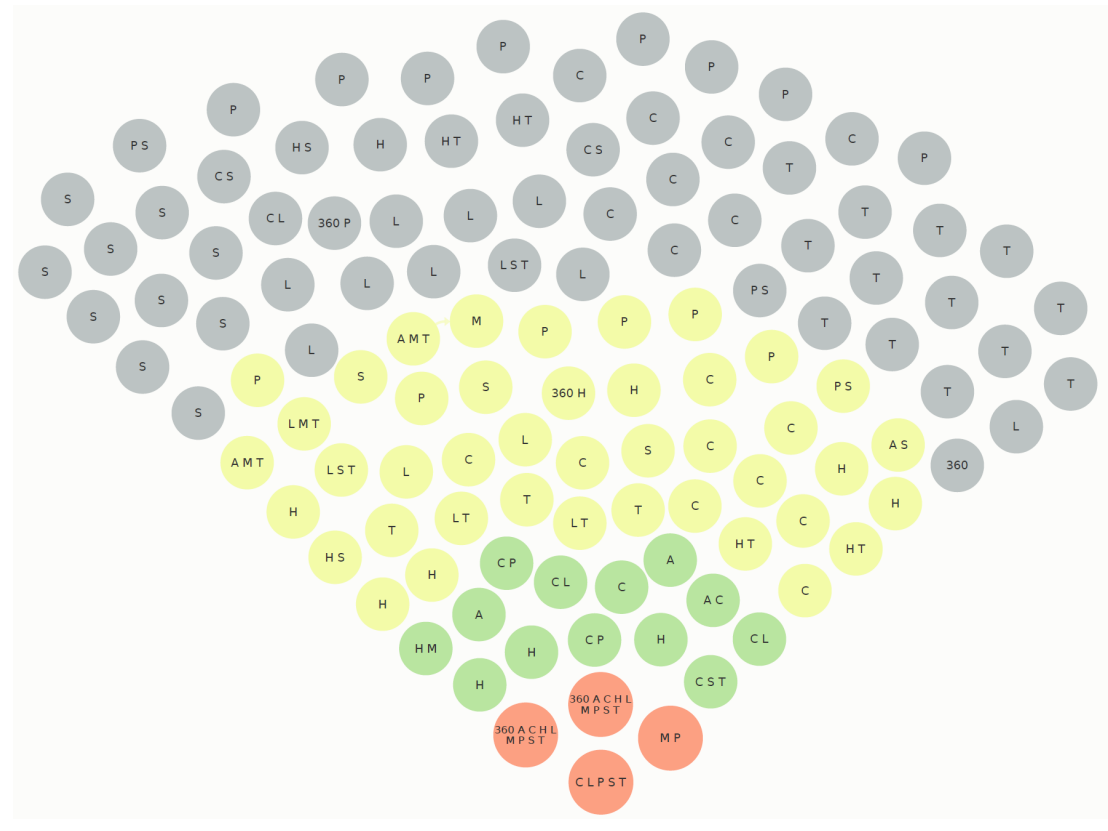

Other impacts in terms of the spread of teaching technologies rising from the group include

- Development of a 360-degree camera library for the College. These cameras have been used in at least nine projects ranging from virtual field trips to lab safety videos to create flexible learning experiences.

- Uptake of wireless presentations from a tablet in teaching spaces to improve student engagement. The lecturer driving tablet rollout in the group also became an advisor to Information Services.

- Roll-out of SRES trial to provide personalised feedback to students in large classes.

- Use of augmented and virtual reality, first shown by a nursing lecturer and now embraced by anatomy academics who became members of the Innovators Group and were nominated for an award for their work.

- Formation of a virtual and augmented reality community of practice as an off shoot of the Innovators Group.

The impact of the group on the preparedness of the College for teaching online during the long lockdown period in 2020 was facilitated by: 
- Discussion of Microsoft Teams in 2018 and contribution to guidelines for staff and students on using Teams when the software was rolled out university-wide in April 2020. A Teams community of practice, chaired by an Innovators member, was launched in February 2021 to support further dissemination.

- Group request for Camtasia Studio screen recording licenses resulted in a university-wide license in 2019 and was followed by several "good practice" sessions for all College staff.

- Construction of the university's first lightboard by an engineer member in 2018. A second lightboard was built in the following year. This technology was used extensively in 2020 to create engaging videos for students and resulted in an Australian Financial Review award.

- Funding for 80 tablet PCs in December 2018 achieved by the College, led to an Innovators member to step up and lead a tablet community of practice. All tablets were loaned to lecturers in 2020 for online teaching.

- Investigation of H5P technology and subsequent participation in the working party and adoption supported across the university.

The impact of the Innovators Group can also be measured in terms of the individual achievements of members. Although originally comprised of largely junior academics at levels A and B, the group has achieved recognition across the College and centrally notably with Information Services and Education Services as "the innovators" who are routinely approached when academic volunteers are needed to assist with design or decision making in learning and teaching at university level. As champions they have: promoted the uptake of new technologies, such as H5P, and access to licenses and services; led bespoke communities of practice, such as the ones for tablets and Teams; and advised on technologies such as the tablet rollout but also on the design of audio-visual environments in teaching spaces. One has taken on the deputy leadership role in learning and teaching in their School, many have been successful with academic promotion. Since the group's formation six of the original 17 have won teaching awards, while 19 members overall have won College or University teaching awards, including one national citation. The work of group members is highlighted on the College L\&T blog tl-she.com.

\section{Discussion and Conclusion}

We have provided a first evaluation of the impact of the Innovators Group so far, including the achievements of individuals and outcomes for the university. More work remains to identify measures of the impact of these innovations, for instance new pedagogical methods, efficiencies recognised in teaching practices and effectiveness of the approach, but also potential resistance. Future analyses will also involve additional data including that from other components of the College initiatives towards creating a culture that values teaching.

The Innovators Group has been more successful than could have been imagined at that first meeting with junior academics who were enthusiastic and full of ideas but were operating in isolation. In our multidisciplinary College, we brought together engineers, nutritionists, microbiologists, and psychologists with the same desire to improve the student experience who quickly learnt to interact and reciprocate by sharing experiences and resources. We took this group aside, supported them, and provided a safe environment to create the desired culture of innovation within this group. Each individual member voluntarily chose the technology they thought would work best for them and so they could share their ideas with others. Members have gained confidence markedly, as shown by their willingness to trial new approaches, to disseminate information and courage to share with others. They are keen to change the practice around them. The group has successfully reduced risk aversion levels in Information Services where they are now allowed to trial unsupported technology and to fail. The culture of innovation that prevails in this group is now "leaking out" to disciplines and departments, as approaches pioneered by members of the Innovators Group are now adopted well beyond the formal group. This observation was called a "ripple effect" in an earlier ASCILITE paper describing blended learning adoption (Borland et al., 2015).

Teaching award applications in the College are more often than ever describing innovative use of technologies in teaching. In mid-2021, while four of the Innovators Group won awards, in total nine individuals or teams were successful with a new category of innovation and impact awards.

We believe key components that made the Innovators Group so effective are

- the safe space that was created for the group to experiment, take risks, and fail, supported by other members and College leadership. This allowed building of a culture of innovation within the group.

- The multidisciplinary nature of the group, and the opportunities to share experiences with others from different backgrounds and levels of expertise but the same passion to improve the student experience.

Sharing experiences enhances the sense of reciprocity and increases confidence to try new approaches (Pataraia 
et al., 2015). The questions we now ask ourselves and that require further consideration and investigation include: What is next for this group? How do we deliberately extend the culture beyond the group and accelerate the "leaking out"? Have we reached sustainability yet? How can we benefit from the abundance of academics who have now experienced the possibilities of online learning and, while keen to go back to face-to-face teaching, want to complement their face-to- face teaching and innovate further? We are collecting data through focus groups with the innovators and are considering completion of the self-assessment tool (Setser \& Morris, 2015 ) to identify how far along the line of "catalyse-enable-sustain" our culture of innovation has progressed.

\section{Acknowledgements}

The authors would like to thank Professor Teri Balser, currently Provost at the University of Calgary, for presenting on HIT and RAT at the ACDS L\&T Leaders Conference, and for further sharing her approach so generously with us in a follow up meeting.

\section{References}

Aldridge, S. (2018). Leading Beyond the Status Quo to Create a Culture of Innovation in Higher Education. https://evolllution.com/managing-institution/higher_ed business/leading-beyond-the-status-quo-to-create-aculture-of-innovation-in-higher-education/

Christensen, C. (2006). What is an organisation's culture? Harvard Business School Case Study 9-399-104.

Elrehail, H., Emeagwali, O.L., Alsaad, A., Alzghoul, A. (2017). The Impact of Transformational and Authentic Leadership on Innovation in Higher Education: The Contingent Role of Knowledge Sharing, Telematics and Informatics. https://doi.org/10.1016/j.tele.2017.09.018

Lewitt, M., Snowden, A. \& Sheward, L. (2014). Developing and Sustaining a Culture of Innovation in Health Higher Education. Literature Review. Council of Deans of Health. The Higher Education Academy. http://www.councilofdeans.org.uk/wp-content/uploads/2014/07/FINAL-Literature-Review-Culture-ofInnovation-clean-v-3.pdf

Borland, R., Loch, B. \& McManus, L. (2015). Implementing blended learning at faculty level - Supporting staff, and the 'ripple effect'. In T. Reiners, B.R. von Konsky, D. Gibson, V. Chang, L. Irving \& K. Clarke (Eds.), Globally connected, digitally enabled. Proceedings ascilite 2015 in Perth (pp. CP:37-CP:41).

Pataraia, N., Margaryan, A., Falconer, I., \& Littlejohn, A. (2015) How and what do academics learn through their personal networks, Journal of Further and Higher Education, 39:3, 336-357, https://doi.org/10.1080/0309877X.2013.831041.

Schein, E. (1988). Organisational Culture and Leadership (San Francisco: Jossey-Bass Publishers).

Schaffer, R. (2012). To Change the Culture, Stop Trying to "Change the Culture". Harvard Business Review. https://hbr.org/2012/12/to-change-the-culture-stop-try.

Setser, B. \& Morris, H. (2015). Building a Culture of Innovation in Higher Education: Design \& Practice for Leaders. Emerging Lessons and a New Tool. In: Next Generation Learning Challenges (NGLC). Breakthrough Model Toolkits. https://library.educause.edu/resources/2015/4/building-a-culture-ofinnovation-in-higher-education-design-practice-for-leaders.

Tierney, W. \& Lanford, M. (2016). Conceptualizing Innovation in Higher Education. Chapter in: Higher Education: Handbook of Theory and Research book series, editor: M. Paulsen. Volume 31. 1-40. https://www.researchgate.net/publication/303208037 Conceptualizing Innovation in Higher Education

Wenger, E. (1998). Communities of practice: Learning, meaning, and identity: Cambridge University Press.

Wenger, E., McDermott, R. A., \& Snyder, W. (2002). Cultivating communities of practice: A guide to managing knowledge: Harvard Business Press.

Winks, L., Green, N. \& Dyer, S. (2020). Nurturing innovation and creativity in educational practice: principles for supporting faculty peer learning through campus design. Higher Education 80, 119-135. https://doi.org/10.1007/s10734-019-00468-3

Loch, B., Thompson, B., Bridge, C., Horey, D., Julien, B., \& Agolli, J. (2021). Building a culture of innovation in learning and teaching technologies through an innovators group. In Gregory, S., Warburton, S., \& Schier, M. (Eds.), Back to the Future - ASCILITE '21. Proceedings ASCILITE 2021 in Armidale (pp. 161-165). https://doi.org/10.14742/ascilite2021.0122

Note: All published papers are refereed, having undergone a double-blind peer-review process. The author(s) assign a Creative Commons by attribution licence enabling others to distribute, remix, tweak, and build upon their work, even commercially, as long as credit is given to the author(s) for the original creation.

( Loch, B., Thompson, B., Bridge, C., Horey, D., Julien, B., \& Agolli, J. 2021 